\title{
Refletindo sobre a modificação corporal em contexto urbano
}

Felipe Moreira*

\section{Resumo}

Este trabalho exploratório buscou compreender o fenômeno urbano da modificação corporal através das contribuições da antropologia ecológica em seus polos interacionais, conflitivos e construtores. Partindo da premissa cartesiana da separação corpo/mente e realocando-a através de estudos contemporâneos, buscou-se entender a situação de agentes sociais que, através de técnicas corporais, adornam seu corpo com tatuagens em um cenário ainda não propenso à aceitação dessa prática e que a pensa em conflito com os seus padrões sociais. Após discutir a tatuagem como marcador social, intenta-se acrescentar as questões de gênero e sexualidade presentes na rede social inked-up.com e seus usuários e usuárias. Esta pesquisa trouxe considerações a respeito das interações e limites sociais das pessoas praticantes da body art, de como se pensam, são pensadas e se projetam no mundo, de forma a causar estranhamento e ressignificar suas relações na sociedade.

\section{Palavras-chave}

Corpo. Modificação corporal. Gênero.

\section{Abstract}

This exploratory work sought to comprehend the urban phenomenon of body modification through ecological anthropology contributions in its interactional, conflictive and constructible poles. Based on the Cartesian premise that separates body and mind and relocating it through contemporary studies, it was intended to understand the situation of social agents that, through corporal techniques, adorne their bodies with tattooes in a social scenery yet not willing to accept this way of life and see it in conflict with their social patterns. After discussing the tattoo practice as a social marker, it is intended to bring questions of gender and sexuality present on the social network inked-up.com and on it's users. This research rises considerations about interactions and social limit of body art practitioners,

* Mestrando em Antropologia pela Universidade Federal de Minas Gerais. E-mail: pileef@gmail.com. 
how they think themselves, how they are thought and how they project themselves in the world, in a way that causes strangeness and re-signifies their relations in society.

\section{Keywords}

Body. Body modification. Gender.

\section{Introdução}

Na ótica cartesiana, ainda hoje muito atual, tanto no senso comum quanto no meio acadêmico, compreende-se o corpo como material passível de se imprimir ideias vindas de cima, ideias nunca completas, pois nunca se há completude, apenas representações registradas no cérebro através dos estímulos. Então, o corpo é entendido como um receptáculo desses estímulos (INGOLD, 2000, p.260), apenas uma ferramenta que a mente, essa "coisa" atemporal, quase ser, possuindo o dom da ação, executa suas vontades (IBID, 2000, p.3) através do corpo. Não nos faltam exemplos de como essa visão ainda é comum e forte hoje em dia, basta olharmos os anseios impressos visualmente nos filmes de ficção científica que trabalham narrativas de inteligência artificial e os inúmeros investimentos econômicos que se têm feito no campo da ciência robótica. Na cultural letrada ocidental, o que valorizamos são as ideias, e como precisamos preservá-las, temos livros impressos, digitalizados e armazenados de forma a durar grandes períodos de tempo, com o intuito de deixar um legado para futuras gerações, legado que até pouco tempo só podia ser passado através da escrita. As civilizações ágrafas e sua história oral puderam, e deram muito, dar conta de inserir a história, tanto corporal quanto mitológica, através de expressões, danças e afins nas suas passagens do tempo sem necessidade de "registrá-las", coisa que só "recentemente" o Ocidente tem feito, graças a novas tecnologias audiovisuais e de comunicação em massa. Diferentemente do Ocidente, nesse processo, nas sociedades ágrafas, a história tem sido rearranjada de inúmeras formas através dos elementos que elas dispõem para perpetuar no tempo (mas sem a imutabilidade opressiva que o funcionalismo lhe legava ${ }^{1}$ )

\footnotetext{
${ }^{1}$ Mudança não no sentido funcionalista que acredita na adaptação para perpetuação das instituições já existentes, e sim no sentido de formas criativas de adaptação cultural às diversas contingências.
} 
suas percepções cosmológicas (o "bricolage" straussiano). No âmbito da arte, a teoria do bricolage é muito esclarecedora, ainda mais quando trabalhamos as questões da dança, pois o corpo age de forma híbrida, tanto como agente quanto como ferramenta, pois nas suas inúmeras combinações que surge o espetáculo da dança. Nesse aspecto, ele quebra com facilidade a dicotomia cartesiana, pois na dança “... o corpo é considerado não mais a sede da alma nem a morada da subjetividade mas, principalmente, a sua expressão mais autêntica e real, é somente por meio dele que se colocam em evidência as intenções e as forces de cada ser humano." (SANT'ANNA, 200, p.20).

Já em se tratando da ciência ocidental, buscamos maneiras cada vez mais congeladas de guardar o tempo ao mesmo tempo dando à sua interpretação uma forma estática e incontestável (basta olharmos para os livros de história escolares, ali encontramos a morte da hermenêutica historiográfica) através de registros audiovisuais que reafirmam a primazia da mente sobre o corpo, pois, ao registrar o movimento em vídeo, temos ali a objetivação de um conceito estabelecido a priori, e a margem de interpretação desse vídeo (excluindo as formas de vídeo-arte das artes plásticas) se torna cada vez menor, pois quem executa aquela filmagem e, respectivamente, as "personagens" ali presentes, em sua maioria, já possuem um roteiro prévio de ação e, provavelmente, quando a exibirem futuramente, tenderão a guiar a quem assiste pela mão e explicar o que está acontecendo ali ou acolá. Ao discutir a diferença entre a pintura e a fotografia, Bazin crê que a câmera, como substituição do olho humano, tende a uma abordagem objetiva, cristalizadora, tanto que o nome da lente se chama "objetiva”. Para ele, a fotografia é uma das formas mais "reais" de se apreender a vida: "Ela age sobre nós como um fenômeno natural, como uma flor ou um cristal de neve cuja beleza é inseparável de sua origem vegetal ou telúrica." (BAZIN, 1993, p.125).

De certa forma, alguns passos foram dados que tornam a sobrevalorização da mente mais frágil justamente pelo fato de que as mesmas tecnologias que foram criadas para poder armazenar dados para a posteridade permitem agora que não mais se gravem ideias somente através da escrita ou da voz, mas também através da imagem e, assim, o corpo poderia voltar à cena e não ser mero coadjuvante no papel de escrever ou falar o que quer que valha a pena ser dito e expressado. Outra forma, não tão recente (especialmente em culturas não ocidentais), mas só ultimamente disseminada (e pouco a pouco mais aceita) de se preservar legados, ideias, pensamentos e vivências tem sido a modificação corporal. Ato híbrido de subjetividade e objetividade sutil, desde as modificações extremas até a "pintura” corporal (tatuagem), 
atua de forma similar à escrita, porém de forma dinâmica e interativa, como será demonstrado mais adiante. O foco deste trabalho se dará nas tatuagens, forma de modificação corporal bastante difundida nos dias de hoje, especialmente nas cidades médias e grandes. Longe de recorrer a uma deformação corporal da tabula rasa lockeana, buscarei compreender que o corpo como ambiente é também um corpo ambientado, utilizandome das dissertações de Ingold sobre o viver no mundo (livelihood) e como esse mundo interage com as pessoas que passam pela modificação corporal da tatuagem. Mas esse mundo onde traçamos (e somos contornados pelas) nossas trajetórias e desvios sociais não é um mundo par e igualitário. Essa reflexão da dissidência será explorada através dos estudos de Bourdieu em complemento com alguns relatos das entrevistas realizadas e outras entrevistas reaproveitadas em trabalhos similares que tratavam da questão do corpo modificado e suas vivências e interações sociais.

Reconheço, porém, que este mundo desigual delineado por Bourdieu possui suas diferentes camadas e significação e relacionalidade. Apesar de ainda perceber uma resistência à prática da modificação corporal, a prática da tatuagem e dos piecings já é um reconhecido nicho de mercado e manifestação cultural difundida, mas não amplamente aceita. Nosso corpo ainda está sujeito a sanções sociais de definições de permissibilidade e tabu. E, no caso da modificação corporal, existem certos conteúdos e locais do corpo que configuram "áreas de contágio”. Essas áreas de contágio definem um espaço de atuação, segundo Douglas (1991, p.31). Assim, possuir tatuagens faciais ou em áreas mais visíveis aloca em um espaço de marginalidade e/ ou lhe define como alguém que trabalha com aquilo. Ainda assim, fora do estúdio de tatuagem, novamente se está sujeito ao olhar discriminatório que não compreende, ao menos no contexto brasileiro, essas práticas fora daquilo com que estamos nos habituando a conviver. Portanto, quando falo de algum preconceito ou atribuição de marginalidade durante o artigo, é sempre pensando de forma relacional à vivência de quem ou de qual grupo está em contato com pessoas praticantes dessas modificações corporais. No caso específico, vejo uma maior resistência da sociedade, pois a rede social em questão não só está inserida neste debate e prática ainda em vias de aceitação social, que é a modificação corporal, mas a conecta com discussões de gênero e de estudos/práticas queer, também novas questões que vêm surgindo em nosso ambiente social e acadêmico. Portanto, se como Le Breton (2011, p.17-18) afirma, a representação social do corpo nos localiza socialmente frente a um sistema de valor, acredito que o fenômeno social da 
modificação corporal, especialmente a tatuagem, tem se tornado uma prática difusa, mas que ainda encontra resistência, pois alguns grupos e pessoas são vistas como "extremas" ao as incorporarem em suas vidas. Porém, trato neste texto especificamente dessas modificações em ligação íntima com questões de gênero e sexualidade, através da plataforma social em questão, o inked$u p$.

O inked-up.com ${ }^{2}$ se apresenta como um "espaço social queer para que pessoas tatuadas, perfuradas e modificadas se conectem, colecionem, se eduquem e inspecionem ${ }^{3}$ ". Conta com a criação de um perfil em que se adicionam fotos (sempre de suas modificações corporais, o que é amplo, pois vai desde modificações no cabelo até tatuagens), fala-se sobre suas modificações, o que faz da vida, enfim, uma descrição ampla de si mesmo. Conta com fóruns de discussão, uma loja online onde as pessoas podem se anunciar, links para sites com conteúdo comum e uma plataforma de bate-papo online onde as pessoas podem conversar mais dinamicamente. Apesar de o conteúdo das modificações não serem sempre relacionadas iconicamente e diretamente a questões de sexualidade e gênero, há uma identificação pessoal com esses temas, principalmente com a proposta queer, já que as pessoas do site se identificam em algum ponto com uma estética que julgam não convencional em seus contextos. Há pessoas com mais de 50 anos extremamente tatuadas e com um visual tido como "agressivo" (como alguns relatam em seus perfis quando há uma discussão sobre impressões sociais no seu dia a dia) tal como barbas longas, cabeça raspada etc. Portanto, o conteúdo estético em si não é completamente queer, mas o conjunto das identidades se agrega de forma em que há um discurso sobre performance queer implícito em grande parte dos perfis e difundido pelo site. Como diz Keyes (2000) a respeito das mulheres negras no rap, o empoderamento vem através da performance em qualquer espaço, performance usada para reconstruir (ou refutar, em caso de conflito) diferentes visões sobre suas identidades. Acredito que fenômeno similar se encontra no caso das modificações corporais, já que é um processo constante. O inkek-up é um espaço, vejo eu, onde as pessoas discutem essas

\footnotetext{
${ }^{2} \mathrm{O}$ site está passando por problemas de hospedagem e, quando fui editar este artigo, seu endereço havia mudado para http://inked-up.ning.com/; mas nem o criador sabe se será temporário ou permanente. Acesso em: 10/03/2013.

${ }^{3}$ Tradução minha: "Inked-Up is a queer social space for tatted-up, pierced-up, and modded-up individuals to connect, collect, educate, and inspect."
} 
identidades, como elas afetam seu dia a dia, como superam seus conflitos ou como se reconfiguram face ao conflito, trocam experiências sobre as diferentes reações e apoios que recebem nos diversos âmbitos sociais que frequentam/transitam, enfim, é um espaço virtual (que porém é usado para marcar encontros 'reais') de afluências e dialogicidades identitárias.

Tem se buscado enxergar na juventude uma forma de contraponto e inovação que nem sempre se sustenta sob o escrutínio crítico, principalmente porque sua premissa é a ideia da globalização modernizadora e seus contraagentes, quase sempre caracterizados com o rosto da adolescência e fases concebidas como pré-adultas. Esteves e Abramovay, citando Ribeiro (p.24), creditam esse imaginário ao século $\mathrm{XX}$, mas hoje ainda podemos ver resquícios dessa visão, principalmente veiculada pela mídia, na moda jovem "transgressora" que dita "novas tendências", indicando um afastamento do tradicional.

A tendência a ver as modificações corporais como uma quebra de padrões convencionais ${ }^{4}$ obscurece a diversidade sempre existente, mesmo em cenários supostamente homogêneos (MOORE apud BLANC-SZANTON, 1997, p.13) e atende mais a um desejo ideológico do que a uma inquisição intelectual. Inserido em um desejo idealizador e permeado pela ótica cartesiana da separação mente e corpo, é comum que o senso comum enxergue a modificação corporal como algo individualista, como um ato de imprimir ideias concebidas pela mente sob um corpo passivo. Vê-se tal força interior, de pouca ou nenhuma interação física com o mundo, se estetizar e se deslocar de um contexto padronizado e se tornar um foco de resistência, evocando uma noção de apropriação particular (ABONIZIO, 2010) e excluindo toda a rede de interações coletivas que subjetiva e objetivamente levam as pessoas a fazerem o que fazem, desde o ato de comer até modificações corporais extremas. É essa rede de interações que não são possíveis de se excluir, seja antes, durante ou após o processo de tatuagem. É esse tipo de visão que neste trabalho será colocada sob análise e então processada e ressignificada.

Há inúmeros processos envolvidos no ato da modificação corporal: os/ as agentes do processo interagem de forma múltipla, seja entre os que se modificaram e os que não se modificaram (com o intuito ou não de fazêlo um dia) e também processos com/entre os modificadores (tatuadores)

\footnotetext{
${ }^{4}$ Até porque as tatuagens podem ser veladas através de roupas e produtos cosméticos disponíveis no mercado hoje em dia.
} 
em si. Para tal, escolhi abordar de forma triádica tais processos, sob a luz das reflexões de Turner e suas inflexões sobre o trabalho de Van Gennep. Entendo como os fenômenos sociais em sua realidade e na vida diária são dinâmicos, múltiplos, heterogêneos e imprevisíveis, porém, como é preciso um recorte teórico, dividirei em três as etapas de análise segundo a lógica pré-liminar/liminar/communitas, consequentemente: a pré-modificação, a modificação (ocorrendo em si) e a pós-modificação. Apesar de a palavra "rito" ser uma categorização científica e não abranger todas as pessoas e a significação que elas dão às suas modificações, será uma categoria útil de análise para aqui discorrermos sobre o assunto.

\section{Pré-Modificação}

A primeira fase, a pré-modificação, é complexa como as outras e até mais problemática. Ela não envolve o total de pessoas sem modificação, mas as que já têm em si o desejo da modificação e assim passam por essa "fase" de inúmeras maneiras e por períodos que podem variar de uma pessoa para outra. Em muitas das entrevistas feitas por Cifuentes (2011), um fator essencial foi o contato com outras pessoas tatuadas; a curiosidade foi se tornando um senso agudo de observação. Assim, não há como determinar causas individuais para o surgimento desse desejo muito menos avaliarmos qualitativamente quão sinceras são as pessoas que dizem querer se modificar. Assim, proponho entendê-las através de uma "educação da atenção", como proposta por Ingold, em que não são os componentes individuais das interações (a tatuagem em si, os tatuados ou o desejo individual do ser que deseja e faz seu cálculo racional de se preparar para uma modificação), e sim nesses todos e muitos outros processos em relação (INGOLD, 2010, p.12). Cabe aqui um contraponto sobre o poder simbólico existente em certos contextos onde essa "educação da atenção" aparece como um poder regulatório e não um propensor cultural e dialógico. Há ainda hoje uma visão marginalizada a respeito das modificações corporais e identificações de seus portadores com criminalidade, mau comportamento, drogas, entre outros (GOUVEIA et al. 2010, p.477). Assim sendo, pode ocorrer justamente uma educação da atenção negativa, ou seja, o que não se deve estimular e o que se deve reprimir. Em alguns casos reportados por Cifuentes, seus entrevistados perceberam reações negativas de pais e mães frente à curiosidade dos filhos e se questionaram se talvez o que eles iriam dizer aos seus filhos não fossem explicações preconceituosas e estigmatizantes. Como afirmou o entrevistado 
do site inked-up, T:, "[...] teve 2 ou 3 casos em que as crianças ficaram com medo de mim, em todos esses casos eram crianças criadas dentro dos preceitos do cristianismo, que é algo que me preocupou."

A decisão ou até mesmo o desejo inicial de se modificar está sujeita ao tipo de interação que se há entre as pessoas modificadas, as não modificadas e ao círculo de interações das pessoas não modificadas que, por sua vez, podem ter influenciado de forma positiva ou negativa sua visão frente às modificações (tal como uma educação da atenção negativa, exposta anteriormente). Nesse mundo de interações de Ingold, encontramos a noção de "sentido imediato do mundo" de Bourdieu (1998, p.9), imposta pelo poder simbólico, limitando (se não até mesmo inibindo) as diferentes percepções, tentando alinhar e direcionar os sentidos frente a um único sentido estabelecido, buscando eliminar e tornar marginal quaisquer outros que possam ameaçálo e transformar a diversidade em só uma palavra sem poder. Outro fator que vale a pena ser mencionado, apesar de não ser focado neste trabalho, é a relação estética que a tatuagem evoca em seus usuários e que causa estranhamento aos que não compartilham tal relação. Além dessa ligação com a marginalidade, há uma identificação com certo dispêndio de tempo juvenil que não é permitido quando se "cresce" e então é preciso "se ajeitar" e buscar o sustento da vida "adulta". A modificação não é compreensível aos que não compartilham dessa visão estética, pois esta “(...) disposição estética só se constitui numa experiência do mundo liberada da urgência e na prática de atividades que tenham nelas mesmas suas finalidades [...]”. Esta visão surge de um pré-conceito ligando à modificação a um certo classicismo que não se partilha na realidade, pois tanto os entrevistados de Cifuentes quanto os do site em questão (inked-up.com) são independentes financeiramente e atuam com certa estabilidade em seus empregos.

Se esse desejo estético se sobressai, se ele aflora na pessoa, começa-se a "[...] identificar el cuerpo como un lienzo vivo y sensible, como posibilidad de expresión artística [...]" (CIFUENTES, 2011, p.187), passamos para a segunda fase a ser analisada agora: o próprio ato de se modificar, de delinear o corpo com as cores da experiência pessoal.

\section{A modificação em ato}

O que exatamente uma pessoa busca exprimir em seu corpo (a palavra "imprimir" denota justamente a visão refutada no começo deste trabalho, sobre colocar para fora algo pensado unicamente por dentro), qual forma, 
cor, localidade, traços etc. são o resultado dinâmico de um emaranhado de relações e ações acontecidas em sua vida, entre seus confrontos e encontros no mundo? Podemos pensar nas considerações de Mauss ao pensar no poder da sociedade sobre o consciente e o inconsciente corporal: "É graças à sociedade que há uma intervenção da consciência. Não é graças à inconsciência que há uma intervenção da sociedade. É graças à sociedade que há segurança e presteza nos movimentos, domínio consciente sobre a emoção e o inconsciente.” (MAUSS, 2003, p.421).

Assim, sendo um ser-no-mundo, apesar de longe de estar definida e acabada, sua personalidade surge como processo dessa emergência (INGOLD, 2000, p.168). Muitos dos relatos dos entrevistados e entrevistadas de Cifuentes apontaram para o desejo de tornar "vivo" um acontecimento passado que marcou bastante a pessoa. Assim, não há como falar em projetos individualistas e preconcebidos como na visão comum sobre a tatuagem, falar dela como uma marca, pois essa marca sempre esteve lá. Ao contrário, seria mais interessante compreendê-la como uma forma de dar cor, de expandir desejos, sentimentos e vontades que nunca deixaram de existir na pessoa, e tais desejos a orientaram e modificaram sua personalidade, suas escolhas e ações durante sua vida. Atuaram, inclusive, na sua relação com o ambiente e a orientam em suas identificações e projetos (IBID, 2000, p.169), a impulsionam a se dedicar ao que quer que seja que a apeteça em suas experiências cotidianas. Ao buscar um estúdio de tatuagem e decidir pela modificação (palavra que também pode ser relativizada, pois até que ponto não estamos nos modificando diariamente? Pela falta de um termo melhor é que a manterei), há um outro fenômeno interessante que diz respeito às críticas de Ingold sobre a separação natureza e cultura: a dor envolvida no ato de se tatuar. A suposta separação da natureza, como algo oposto ao reino da cultura, sendo a cultura como algo próprio do homem e a natureza um imponderável constituinte, mas não constituído pelo ser humano, (antes um lugar a ser dominado antes de habitado), sofre um ataque quando pensamos na relação existente entre a dor (considerada "biológica", é uma reação "química" do corpo frente a uma ação supostamente danosa ao corpo onde são acionados mecanismos para controlar este choque) e a tatuagem. Deliberadamente, se escolhe suportar tal dor em prol de um desejo estético que não é uma "necessidade fisiológica”. Não é uma dor "necessária”, e sua intensidade não é a mesma em todas as pessoas. Nos relatos de Cifuentes, alguns entrevistados afirmaram que, após a sua primeira tatuagem, começaram a ter outra relação com a dor não só durante e depois das outras tatuagens, 
mas com várias outras experiências de dor física, portanto não há como dizer que a dor é algo "natural" se há tanta variação. Se, como Ingold afirma, o ambiente nunca está completo e é tecido através das atividades dos seres enquanto vivem e estão continuamente sendo construídos e reconstruídos, juntamente com esses seres (IBID, 2000, p.20), há no estúdio de tatuagem um ambiente constitutivo e constituinte de relações, tanto entre pessoas quanto entre pessoas e situações. Diferentemente dos demais locais, ali no estúdio de tatuagem a dor é algo que constrói o ambiente e vice-versa, pois nos outros lugares a dor é uma quebra, é algo a ser suprimido e evitado:

Ora, a marcação do corpo corresponde a uma experiência estética que se sente (na dor que impli $\neg$ ca) e que faz sentir (emoções como repulsa, fascínio, medo, desconfiança, curiosidade, etc.). A sensação de dor que a invasividade implica, confere um suplemento de realidade à acção de marcar o corpo, uma forma de intensificar uma existência individual através da estimulação de uma nova vivência do corpo vivo, numa cultura em que a dor é, por defeito, uma realidade a ser suprimida, uma sensação a ser anestesiada, signo emocional de sofrimento e patologia, passível de ser medicalizado e controlado. (FERREIRA, 2007, p.236).

No ambiente do estúdio, o que se inscreve não são histórias no corpo, como uma página em branco, tais histórias sempre estiveram lá e foram construídas, "tecidas", para usar uma expressão de Ingold, juntamente com ciclos de vida dos demais componentes da trajetória social das pessoas (INGOLD, 2000, p.199). Não se tatuam ideias e experiências no corpo, elas sempre estiveram lá ${ }^{5}$. Apenas foram ligadas às linhas de coexistência de diversas formas e cores diferentes, criando mosaicos vivos e mutáveis no corpo, que, como o corpo, passam pela existência mundana, interagem e aprendem com as experiências cotidianas. Mas assim como as relações e trajetórias de vida podem levar a pessoa, na primeira fase, a repudiar, ter preconceito, receio ou medo de encarar um estúdio, a fase intermediária também está marcada por relações de poder desiguais. Mesmo após a decisão de se modificar e sentar em um estúdio para tatuar, pode ocorrer um retrocesso devido ao medo e preconceito, pois ali se torna cada vez mais inevitável a marca que se irá ter

\footnotetext{
${ }^{5}$ PupDon, usuário do site inked-up.com, diz que suas tatuagens não eram a realização de uma pessoa nova e sim um sinal de seu crescimento como "leatherman" (praticante de bondagedomination-sadism-masoquism - BDSM), que já estava florescendo antes do processo de modificação.
} 
para toda a vida (por mais que ela não seja estática, ainda assim é uma marca de diferenciação, é um fator agregado à vida, mesmo dinâmico e que possui um certo valor simbólico variado de contexto para contexto - da admiração e identificação ao repúdio e marginalidade). O peso do passado se impõe e pode haver retrocesso na decisão. Há também a questão de nossa sociedade repousar em um sistema de leis que definem a legalidade penal que limita a ação das pessoas, ou seja, é preciso ser maior de 18 anos para se fazer uma tatuagem. Tanto a maioridade penal quanto a desistência guiada pela culpa e medo são atualizações de um “... passado que sobrevive no atual e que tende a se perpetuar no porvir ao se atualizar nas práticas estruturas de acordo com seus princípios" (BOURDIEU, 2009, p.91). Uma das características do habitus. Impondo sua própria lógica à incorporação (IBID, p.94), pode inclusive impor sua neutralidade e impedir a aquisição de símbolos que lhe sejam danosos. A medicina também atua como um saber instituído e, ainda como no século XIX da França foucoultiana, busca vigiar, delimitar e ganhar poder (FOUCAULT, 2008) através das prevenções técnicas, físicas e das remediações das doenças.

\section{A pós-modificação}

A terceira e última fase (analítica, cabe frisar, pois no mundo "real" ela é de longe a mais complexa e dinâmica) é o término, a pós-tatuagem. Ela é, acredito, como a transição no pensamento de Ingold, do "building" para o “dwelling” (INGOLD, 2000, p.173), pois, com a tatuagem, há uma simbolização do "morar" em seus próprios sentimentos, vivências, experiências, dores e prazeres ou a sensação de tê-los expandido. Perguntado sobre o significado e a relação entre suas tatuagens e sua vida, o entrevistado PupDon. responde: "A tatuagem completa celebra quem eu sou como um ser sexual e cada um destes personagens são lados diferentes de minha personalidade, são todos lados de mim. E eu os amo e uso com orgulho". Praticante de bdsm (bondage, domination, sadism \& masoquism, formas de "fetishes" sexuais), PupDon. decidiu transpor e colorir seu corpo de acordo com suas vivências, que estão longe de se adequar à lógica cartesiana de que falamos mais cedo, pois não foram as ideias que ficaram inscritas no corpo de PupDon. e sim suas vivências, tanto mentais como corporais, pois a sexualidade que ele expõe em seu corpo foi incorporada através das práticas que ele viveu e vive. Suas tatuagens relatam cenas corporais de sexo dentro da lógica do BDSM. Se não temos acesso completo às sensações alheias, suas representações, ao contrário, são públicas (IBID, p.158). Sendo públicas, estão sujeitas às 
múltiplas interpretações e significações, o que já as torna dinâmicas, pois há uma relação entre espectador e tatuado que pode significar mudanças relacionais de abordagem ou até mesmo modificar relações já existentes.

Outro fator interessante é a mudança na autoestima e uma mudança na relação introspectiva do tatuado. Em diversos relatos de Cifuentes e nos questionários aplicados apareceu a questão da "tomada do corpo". Como diz T, houve uma "[...] sensação de pertencimento - algo como "esse corpo é meu" - se tornou maior ou talvez a consciência disso tenha se pontuado." Relatos congruentes com a visão de Ingold sobre a incorporação e não inscrição do ambiente em nossos corpos, e vice-versa. (IBI, p.193). Esse sujeito que do estúdio sai, não novo, mas renovado, como quem não só restaurou, mas amplificou sua vivência na pele e sobre a pele, não só está coberto pela poética integralista de Ingold ao viver sua vida "lá fora", mas também está sujeito a atritos decorrentes de um mundo desigual. Apesar de a moralidade atual não se fazer totalmente imponente e haver momentos de aceitação e até mesmo apreciação das modificações corporais, são momentos incomuns apontados pelas entrevistas em que apenas as pessoas mais próximas, no geral, aprovam, respeitam, toleram ou até admiram as modificações ocorridas. Como PupDon apontou em sua entrevista, pelo teor sexual de suas modificações, até apreciadores de tatuagens têm certos problemas em compreender as expressões sexuais desenhadas em seu corpo.

Esses momentos incomuns podem ser entendidos como erros e falhas momentâneas do habitus (WACQUANT, 2007, p.9), o que explicaria também o medo e retrocesso de pessoas que já se decidiram por tatuagens e no momento de se tatuar desistem e voltam atrás. Pode ocorrer também um fenômeno parecido, não de falha, mas de apropriação, que define e "legaliza" certas práticas sociais em função de outras. O habitus pode incorrer na falta de controle total sobre situações que possam lhe ameaçar, em adaptações e escolhas seletivas, influenciando e estimulando certo tipo de tatuagem em função de outras:

[...] o habitus tende a garantir a sua própria constância e sua própria defesa contra a mudança mediante a seleção que ele opera entre as informações novas, rejeitando, em caso de exposição fortuita ou forçada, as informações capazes de questionar a informação acumulada, e principalmente, desfavorecendo a exposição a tais informações. (BOURDIEU, 2009, p.100)

Por fim, é esse corpo renovado que, apesar das adversidades de um ambiente ainda não preparado para sua atuação inovadora e justamente 
porque essa inovação fere seu preconceito, transita no tempo e no espaço tecendo diferentes relações, fazendo da sua história corporal um convite a um novo olhar sobre as relações dos, entre e com nossos corpos. A história corporal que está sendo escrita e pavimentada pelas modificações corporais, como diz Ingold, vem através do fascínio criado pelas cores, formas e diferentes traços das tatuagens, fazendo com que os ouvintes e leitores sejam atraídos (INGOLD, 2000, p.190) e cobertos pelas suas direcionalidades. A atenção é voltada para o corpo e tudo o que ele representa e pode representar, seja através de suas marcas naturais, acidentais ou propositais, como a tatuagem. É um convite involuntário quando se está transitando no mundo, porém é um convite a uma história incompleta e passível de mudanças. E essas mudanças são mudanças de um corpo ambiente, um corpo que se modifica modificando o próprio ambiente em que transita, ou seja, é um corpo ambientado também. No processo agencial onde, em um ambiente, o sujeito cobre o mundo reciprocamente e age nesse processo de "habitação" espaçotemporal, há interatividade (IBID, p.199) e interação. As modificações corporais não respondem meramente a um planejamento interno do sujeito que passa suas "ideias" ao tatuador e que então as executa como um operário o que foi concebido na "planta". Ao contrário, as modificações refletem sua vivência social, estavam inscritas no corpo muito antes que as escrevessem com tintas. Se muito, no máximo ocorreu uma colorização do que sempre esteve ali, um contorno de experiências interligadas que agora exibem o que antes estava por dentro. A mente, as sensações, as ideias e os sentimentos nunca estiveram "dentro da cabeça", mas no mundo (IBID, p.3), agora ornados com as mais diferentes formas e espectros estéticos possíveis. Há interação com o novo, com este mundo, aborda-se o diferente, há curiosidade. Essa curiosidade, se sincera e guiada por espírito inquisitivo livre de preconceitos (cenário não tão comum em nossa sociedade atual), pode gerar relações mais iguais e legitimar, alimentar ou desestigmatizar desejos reprimidos, fazendo com que as pessoas reinventem seus corpos à medida que os exibem, transgridam e coloram suas trajetórias de vida.

\section{0 queer e a corporeidade}

Reconversão, deslocamento, reconfiguração, subversão e performance. Expressões utilizadas pela teoria queer para não só compreender, mas transformar a sexualidade humana, indicando performatividades que reapropriam marginalidades antes ofensivas para ostentá-las como provocação frente ao insulto, incorporando-as como identificação oportuna ao debate 
científico e social (PEREIRA, 2008, p.500). Dentro dessa lógica, não basta apenas entendermos que as discriminações de gênero e sexuais têm um lugar definido pela heteronormatividade, que há um tempo-espaço reservado para as pessoas de acordo com seu sexo, gênero e sexualidade. No percurso do desenvolvimento humano, inúmeras instâncias sociais definem o caminho para que se atinja o ideal humano de ser social. Nesse caminho, as baldeações são segmentares, a primeira parada é o sexo e, de lá, parte-se rumo ao gênero para, por fim, baldear-se para a última estação, a estação da sexualidade. Essa pressuposição regulatória entre sexo, gênero e sexualidade (LOURO, 2009, p.90) são relocações necessárias para que se atinja o destino: a normalidade. $O$ corpo é aí domado de forma a retratar seus gametas femininos ou masculinos de forma predeterminada pelo nascimento. Nesse percurso, aprende-se a adequar os hormônios junto a expectativas sociais de comportamento e relação com seus pares, direcionando seus desejos, impulsos sexuais, tesões e tensões somente onde lhes é devido. Não vamos aqui discutir as teorias e discussões de gênero e sexualidade. Essa pequena apresentação tem o intuito de esboçar o que é a heteronormatividade (o sistema sexo-gênero-sexualidade) e as expectativas sociais acerca dos papéis de gênero para que entendamos a pauta contra-hegemônica do site em análise.

Dentro desse quadro sociorregulatório dos comportamentos sociais gostaria de trazer a experiência do site inked-up.com, lugar que, analiticamente, não só denuncia a exclusão heteronormativa, mas busca confrontá-la através da subversão corporal, usando o corpo como espaço de luta, encarnando na epiderme manifestos contra a normatização dominante, como fuga à prescrição, entendendo o corpo como potencialidade de reinvenção e combate à heteronormatividade (FERREIRA, 2007, p.298).

As contestações de teorias e de teóricos feministas e queer se voltam para a ideia funcionalista do corpo-estático. Dentro dessa ideia, lê-se o corpo como tabula rasa pronta para ostentar símbolos e signos de uma determinada cultura, de forma acrítica, compactuando com um ideal de sociedade monolítica e sem rupturas internas. A corporeidade é então vista como passividade motora, que, apesar de se movimentar e transitar em diversos espaços e instâncias socioculturais, apenas reproduz a desigualdade das posições e estruturas sociais, constatando relações assimétricas de poder existentes, sejam elas de classe, gênero, raça etc. (FERREIRA, 2007, p.291292). Dentro dessa lógica, o próprio corpo pode ser entendido não só como portador dessas desigualdades, mas também objeto delas, configurando-se como mero artifício expropriado por uma sociedade desigual. Retira-se do próprio corpo sua capacidade de transformação e mobilidade, definindo 
quando, onde e como transitar. Porém, o corpo está longe de ser mero efeito/objeto de um sistema fechado e é entendido aqui como potência, como alavanque para uma desestabilização desse status quo, principalmente no que se refere à sexualidade.

$\mathrm{O}$ ato de se tatuar e se reinventar constantemente evoca não só um protesto contra a usurpação do corpo mas também contra a própria ideia de modelação padronizada corporal. A heteronormatividade rechaça a criatividade, quer fechar o circuito das sensibilidades humanas de forma perfeita, porém, quanto mais se conhece o corpo, mais se indica o caminho da impossibilidade de dominar por completo suas vivências, sua motricidade e suas descobertas (SILVA, 2006, p.40). E nessa lógica de reinvenção, de reconfiguração e deslocamento já mencionada é que se verifica a ousadia e o protagonismo do inked-up.com. Seus usuários ressignificam sua vida de forma a marcar em suas peles um protesto contra a presunção heteronormativa, criam formas de não só se reapropriarem de seu corpo como bem entenderem, mas também de resgatar aquilo que lhes é de direito, a noção de que o corpo é propriedade exclusiva de seu portador e que nele exibem-se marcas de sua identidade e experiência de vida, por mais que estas não se adaptem ao que é esperado convencionalmente (ABONIZIO, 2010, p.7). O site em questão possui usuários que se identificam com uma comunidade queer e modificada, trocam experiências via fórum, exibem as fotos de suas alterações corporais, criam tópicos e comunidades de assuntos diversos, ligados ou não à modificação corporal, criando redes virtuais de sociabilidade e vivências, virtuais ou não. A própria afiliação ao site (que, cabe salientar, é gratuita), pressupõe essa identificação com o que é abjeto em nossa sociedade, a sexualidade desviante, e já cria, assim, um foco de resistência reforçado pela adoção desse padrão dissidente de comportamento não só na filiação ao site, mas na marcação de seus corpos com tatuagens que quebram essa hegemonia sexual. Podemos citar como exemplos perfis que compartilham fotos de tatuagens em seus corpos como o triângulo rosa invertido (Imagem $1 \mathrm{em}$ anexo) tatuado na virilha, como símbolo da resistência queer (símbolo antes utilizado para identificação de homossexuais nos campos de concentração nazistas); patas de urso estilizada, símbolo de identificação com o movimento bear, contestando a padronização da beleza homossexual masculina (essa comunidade se compõe de gays que contestam o que entendem como padrão de beleza gay, ou seja, músculos, corpos sem pelos etc.); o símbolo do movimento punk hibridizado (Imagem 2 em anexo - explicação do símbolo dada pelo usuário do site com a tattoo) com o símbolo grego do masculino, representando contestação dessa sociedade expansiva e capitalista que busca 
mercantilizar até mesmo a sexualidade ou desenhos que mostram pessoas envolvidas em práticas de dominação e bondage (Imagem 3 em anexo). Além das reapropriações positivas de termos pejorativos pelo movimento queer (como slut, fag, o próprio queer etc.), se pensarmos com Butler (2002), podemos ver nessas tatuagens iconoclastas subversivas um análogo corporal dessa estratégia textual-identitária.

Esses exemplos citados, ao mesmo tempo em que extrapolam o reino do individual e exibem uma contraestética desafiadora aos padrões atuais, desenham em seus corpos símbolos que vão na contramão da hegemonia sexual (SABINO; LUZ, 2006, p.254). Desafiam não apenas o binarismo generificante da sociedade, contestam não apenas os desígnios sociais do que é "ser homem" ou "ser mulher", mas, à luz dos estudos queer, brincam e bagunçam com tudo o que tange a sexualidade humana. Não querem apenas evidenciar essa opressão que delineia um caminho direto à normalidade, mas buscam, através de suas cartografias corporais, mostrar que nunca houve e nunca haverá tal rodovia ligando a sexualidade humana a um destino de normalidade. Os usuários e usuárias do site, não se dobrando ao normativo sexual, trazem uma nova experiência de compreensão da sexualidade humana. Ao se empoderarem de suas sexualidades e resgatarem seus corpos, mostram que não há rota para a sexualidade, que ela nunca se desviou de seu caminho e que sempre lhe tentaram apontar uma direção que nunca existiu e que provavelmente nunca existirá.

\section{Referências}

ABONIZIO, Juliana.

(2010). Aparências ímpares: Um estudo sobre os modos de ser e aparecer dos usuários de modificações corporais extremas. Ponto Urbe, n.6

ABRAMOVAY, Miriam; ESTEVES, Luiz Carlos Gil. (2008). Juventude, juventudes: pelos outros e por elas mesmas. VI CONGRESSO PORTUGUÊS DE SOCIOLOGIA. Anais do VI Congresso Português de Sociologia. Lisboa: p. 1-14.

BAZAN, Andre.

(1993). Ontologia da Imagem Fotográfica. In: Ismail Xavier (Org.); A experiência do cinema. Rio de Janeiro: Graal. p. 121-134.
BOURDIEU, Pierre ; SAINT-MARTIN, M.

(1976). Gôuts de classe et styles de vie. Actes de La Recherche em Sciences Sociales, n. 5, p. 18-43.

BOURDIEU, Pierre.

(2009). 0 senso prático. Petropólis: Vozes.

(1998). O Poder Simbólico. Rio de Janeiro: Bertrand Brasil.

BRAGA, Sandro.

(2009). A tatuagem como gênero: uma visão discursiva. Linguagem em (Dis)curso - LemD, v. 9, n.1, p. 131-155. 
BUTLER, Judith.

(2011). Cuerpos que narran: La práctica del tatuaje y el proceso de subjetivación. Revista Diversitas - Perspectivas En Psicología, vol. 7, n. 1. 179-191.

(1993). Bodies That Matter: On the Discursive Limits of Sex. London: Routledge.

FERREIRA, Vitor Sérgio.

(2010). Tatuagem, Body Piercing e a experiência da dor: emoção, ritualização e medicalização. Saúde Soc., São Paulo, v.19, n.2, p.231-248.

(2007). Política do corpo e política de vida: a tatuagem e o body piercing como expressão corporal de uma ética da dissidência. Etnográfica, vol. 11, n. 2, p. 291-326.

DOUGLAS, Mary.

(1991). Pureza e perigo. Lisboa: Edições 70.

FOUCAULT, Michel.

(2008). Microfísica do Poder. São Paulo: Graal.

Gouveia, Valdiney; Medeiros, Emerson Diógenes; Mendes, Luís Augusto de Carvalho; Vione, Kátia Correa; Alves, Rebecca; Athayde, Aguiar.

(2010). Correlatos Valorativos de atitudes frente à tatuagem. Psicologia \& Sociedade, vol. 22, n. 3, p. 476-485.

INGOLD, Timothy.

(2000). The perception of the environment: Essays on livelihood, dwelling and skill. London: Routledge.

INGOLD, Timothy.

(2010). Da transmissão de representações a educação da atenção. Educação, Porto Alegre, v. 33, n. 1, p. 6-25.

LE BRETON, David.

(2011). Antropologia do corpo e modernidade. Rio de Janeiro: Vozes.

LÉVI-STRAUSS, Claude.

(1989). 0 Pensamento Selvagem. Campinas, SP: Papirus.

CHERYL, Keyes.

(2000). Empowering Self, Making Choices, Creating Spaces: Black Female Identity via Rap
Music Performances. The Journal of American Folklore, vol. 113, No. 449. p. 255-269.

Lise, Michelle Larissa Zini; Cataldo Neto, Alfredo; Gauer, Gabriel Jose Chitto; Zogbi, Hericka; Dias, Jorge; Pickering, Viviane Leal.

(2010). Tatuagem: perfil e discurso de pessoas com inscrição de marcas no corpo. Na Bras Dermatol.vol. 85, n. 5, p. 631-8.

LOURO, Guacira Lopes.

(2010). Gênero, sexualidade e educação: uma perspectiva pós-estruturalista. Petrópolis, RJ: Vozes.

MAUSS, Marcel.

(2011). As Técnicas Corporais. In: Marcel Mauss; Sociologia e Antropologia. São Paulo.

Pereira, Pedro Paulo Gomes.

(2008). Corpo, sexo e subversão: reflexões sobre duas teóricas queer. Interface - Comunic., Saúde, Educ., v.12, n.26, p.499-512.

SABINO, César; LUZ, Madel.

(2006). Tatuagem, Gênero e Lógica da Diferença. PHYSIS: Revista de Saúde Coletiva, vol. 16, n. 2, p. 251-272.

SANT'ANNA, Denise.

(2006). É possível realizar uma história do corpo?. In: Carmen Soares (Org.); Corpo e História. Campinas: Autores Associados. p. 3-23.

SILVA, Ana Márcia.

(2006). A natureza da physis humana: indicadores para o estudo da corporeidade. In: Carmen Soares (Org.); Corpo e História. Campinas: Autores Associados. p. 25-41.

TURNER, Victor

(1974). 0 processo ritual. Petrópolis: Ed. Vozes.

\section{Recebido em}

maio de 2014

\section{Aprovado em}

agosto de 2014 


\section{Anexo}

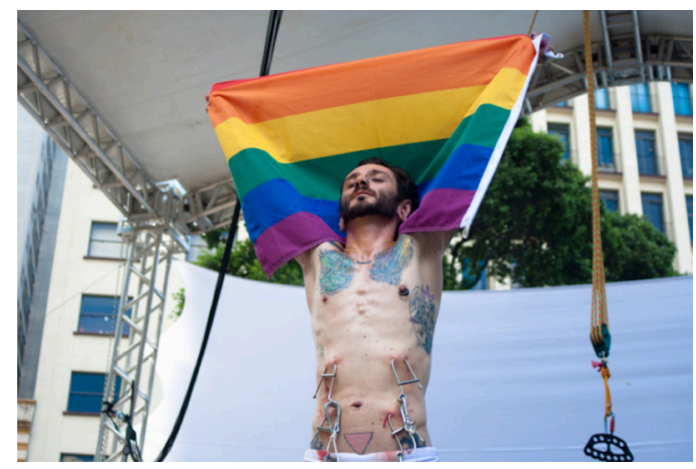

Imagem 1: Triângulo queer.

Fonte: www.inked-up.com

Acesso em março de 2012.

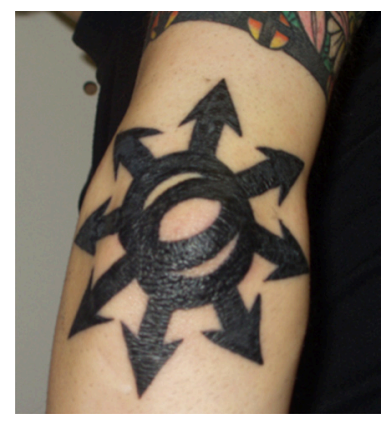

Imagem 2: Greek punk

Fonte: www.inked-up.com

Acesso em março de 2012.

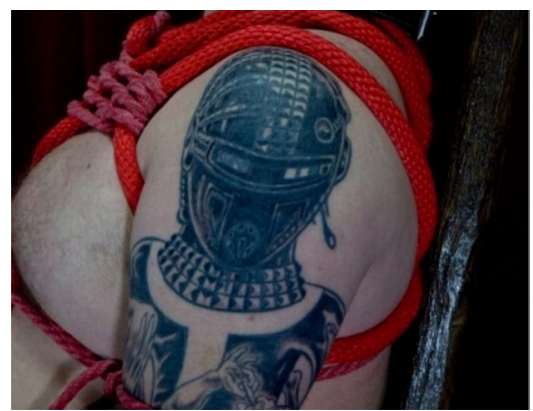

Imagem 3: Bondage PupDon Fonte: www-inked-up.com Acesso em março de 2012. 